\title{
Marketing and Politics: Strange Bedfellows no More
}

\section{David A. Schweidel ${ }^{1} \cdot$ Neil Bendle $^{2}$}

Published online: 23 November 2019

(C) Springer Science+Business Media, LLC, part of Springer Nature 2019

There has always been common ground between marketing and politics [8]. It's not difficult to envision the application of marketing theory and practice to political campaigns given there are many tactical question to address. What message will resonate with the target audience? How do we best allocate the media budget given the constraints faced by the campaign? How best can we sell the political product? [14] Advertising, public relations, and message control have long been thought key to success. For those taking a more inclusive view of marketing then how the political product is developed is seen as critical. This means involving voters in policy but how exactly should input be sought?

Another exciting feature of the political landscape leads to strategic challenges which are, if anything, even more complex than for commercial marketing. Often multiple stakeholders must be satisfied. The US primary system makes this tension immediately apparent; the population of primary voters is not the same as the population of general election voters [1]. Is it best to adopt more extreme policies for the primary? Is moving back to the center for the general election possible? Will this look inauthentic? Is a consistent position more appealing to the voters even if the majority will not always agree with you on every issue?

These questions relate to traditional political campaigns but the application of marketing to running campaigns is not the only source of intersection between these disciplines. We now see brands making decisions that can be seen in a political light. Nike's ad campaign featuring Colin Kaepernick is but one example of this. The social media commentary surrounding such decisions, and the firm's subsequent financial performance,

David A. Schweidel

dschweidel@emory.edu

Neil Bendle

nbendle@ivey.ca

1 Goizueta Business School, Emory University, Atlanta, GA, USA

2 Ivey Business School, Western University, London, ON, USA suggest the power and danger of a close association between a brand and a political idea/movement. While some firms may adopt overtly political stances, given the heightened polarization in the United States, one can see many more mundane decisions enacted by marketers being interpreted as taking a political stance. An obvious example might be Target's move to gender-neutral bathrooms which, for some reason, proved to highly politically charged [13]. This special issue of Customer Needs and Solutions aims to stimulate research with a political focus and embraces a variety of perspectives around the intersection of politics and marketing.

\section{Political Campaigns and Marketing}

The overlap between marketing and politics has been thrust into the spotlight in recent years, but these two disciplines have been intertwined for decades. Today, brands commonly engage in targeted marketing through digital channels including Facebook. While the most recent presidential campaign put a spotlight on the practice of targeted marketing, the underlying methods themselves are not new. In the 2004 presidential election, "micro-targeting" was employed [4]. The premise was simple: "Take corporate America's love affair with learning everything it can about its customers, and its obsession with carving up the country into smaller and smaller clusters of like-minded consumers, and turn those trends into a political strategy" [4]. Hillary Clinton's chief strategist and pollster in her 2008 campaign, Mark Penn, even wrote a book a successful on the crossover of political and marketing segmentation [16].

In essence, the approach common to marketing and politics is to segment the market and target consumers/voters with the message that would most resonate with them. Fast forward to the 2016 election season, again political campaigns were taking a page from corporate marketers' playbooks. Only this time, the technique de jour was digital marketing. Though Facebook and Google are now able to gain greater insight into the deepest corners of consumers' lives thanks to the digital exhaust we all produce while going about our daily activities, 
targeting consumers online operates in the same manner as message targeting with older technologies. In this, marketers identify clusters of similar consumers and send them the message that will most appeal to them. Beyond trying to persuade consumers to vote, the same tactics can be used by the political campaigns in soliciting donations.

Given the widespread adoption of marketing techniques by political campaigns, Sridhar Moorthy in this issue [15] provides a comparison between marketing applied to traditional commercial settings and political marketing. Grounding his discussion in the 4 Ps, Moorthy puts his attention on "product" and "promotion," as "place" (distribution) and "price" are less applicable to the political context. Moorthy's juxtaposition of marketing strategy in commercial settings and electoral politics shows an example of such research and Jennifer LeesMarshment [11] advocates that marketing scholars should focus on the political arena. She offers exemplars of how marketing has been applied to the political domain in terms of developing a messaging strategy (e.g., Tony Blair's slogan New Labour, New Britain for his 1997 campaign and Barack Obama's 2008 slogan Yes We Can), conducting research (e.g., microtargeting by Michael Bloomberg's campaign for mayor of New York City), organizing a campaign (e.g., grassroot efforts undertaken by Presidents Bush's and Obama's campaigns) and communicating with prospective voters and the constituents of elected officials (e.g., Justin Trudeau's Instagram activity and New Zealand Prime Minister John Key's defense of a tax increase). While there are clear similarities between the marketing of products/services and politicians, Lees-Marshment also raises important ethical considerations for marketers to consider.

In making her case for the importance of marketing scholars probing political issues, Lees-Marshment notes that it offers an opportunity for the marketing discipline to "fulfill the social obligation to study the marketing of politics which has a profound influence on society." Given the importance of politics in the discourse within, and between nations, and its role in shaping society, we could not agree more with the fundamental importance of deepening our understanding of how politics employs marketing methods and their effects on consumers/voters.

\section{Empirical Marketing Research of Political Contexts}

This is not to say that marketing has previously been absent from the political realm. Quite the contrary! Mitch Lovett [12] offers a review of empirical research that has been conducted on political marketing. Drawing on economics, political science, marketing, information systems and communications, he provides an accessible primer to researchers who are new to the area. He offers an overview of key areas of research that have been probed in extant research, which include:

- The effects of political advertising and heterogeneity in these effects

- Disentangling turnout vs. candidate choice

- The impact of grassroot efforts

- Campaign targeting and messaging decisions

- The role of digital and social media

In addition to identifying well-developed areas of research, Lovett also points readers to the main sources of data that have been used in prior research. While there is already work being undertaken using social media data [2], Lovett identifies voting and demographic data, advertising data and media coverage as the main sources of data for extant research. This combination, interesting and important questions with available data, points to the tremendous opportunity in the political domain for empirical researchers in marketing. Given the burgeoning sources of data, including but not limited to visually-oriented social media platforms such as Instagram, mobile location data and online social networks, the political context offers fertile ground for the application of both new empirical methods and data sources.

\section{Politics and Brands}

Moorthy, Lees-Marshment, and Lovett offer a grounding in our knowledge of political marketing to date and call for additional work in the area. Echoing that call, in 2018, Georgetown University's McDonough School of Business hosted Data, Dollars and Votes: The Intersection of Marketing and Politics to foster exploration of the growing overlap between politics and marketing.

One of the topics that received attention during Data, Dollars and Votes was the role of branding in politics. This can be viewed from two different angles. Taking first the use of branding in a political campaign, the paper by Beth Fossen, David Schweidel, and Michael Lewis [6] applies the notion of the human brand [18] to political candidates. The authors quantify the value of the brand in terms of a performance premium. That is, controlling for other sources of variation in performance, to what extent does the candidate exceed (or fall short) of expectations. Using data from the House of Representatives over multiple election cycles, the authors quantify an individual's brand equity based on the systematic over- or under-performance relative to expectations.

Having looked at how a marketing perspective can be applied to political campaigns, this special issue turns to consider how politics may affect marketing more broadly. Chris Hydock, Neeru Paharia, and T.J. Weber [7] take up this question with regard to corporate political advocacy (CPA). Drawing on the 
literature on consumerism, corporate social responsibility and political orientation, the authors both provide a review of existing research on CPA and point to opportunities to for future research in CPA. One area that may provide firms with much needed guidance on publicly taking stances is to understand how the characteristics of the company and its customers will impact consumer response to CPA. Returning to the discussion of Colin Kaepernick's partnership with Nike, while the company faced its share of criticism that included consumers burning their shoes in protest, its stock price surged. There was an increase of the company's value by $\$ 6$ billion dollars in the 2 weeks after the airing and Nike received creative accolades [5]. Many would see Nike as an example of corporate political activism that benefited the bottom line. A reasonable question is whether it progressed any social agenda.

As brands weigh whether or not they want to take a stance on politically-charged issues, fundamental to this decision is an understanding of the brands' customer base. Outside this special issue research is currently being performed in this area. For example, in the case of brand crises, those who are engaging with the brand for the first time may differ markedly from those who have engaged with the brand previously [21]. With an understanding of who is actually buying a brand's products, marketers can assess the risks associated with tackling potentially controversial issues. This fits with other promising work [17] which assesses the political leanings of a brand's social media followers. Brands with customer bases that are primarily of a single party may face less opposition to views that are supportive of their politics, whereas those with less polarized customer bases may elect to avoid alienating their customers. In a climate in which political divisiveness remains in the news, it may become more difficult for brands to avoid their actions being seen through a partisan lens. This raises important questions around how brands can safely navigate this terrain.

\section{Data and Technology}

One of the forces reshaping marketing is the availability of detailed consumer data [19]. The extent to which marketing may be personalized relies in large part on the data that technology firms such as Amazon, Facebook and Google, to name but a few, have acquired about consumers. It is not simply the availability of data on its own that has precipitated a seismic shift in the extent to which marketing content may be targeted at individuals. Direct marketing, for example, has relied on consumer segments constructed using third-party data from vendors such as Axciom for years. An important difference now is the way in which marketing analytics are being conducted on rich consumer data and deployed at scale thanks to advances in technology. This was illustrated recently as details have emerged about the ways in which then-candidate Trump's campaign leveraged Facebook in its 2016 success
[3]. From profiling and segmenting voters, to deploying precisely targeted advertisement and measuring users' engagement with the advertisements, like the work of commercial marketers, political campaigns can conduct digital marketing with greater precision.

As with many technological advancements, there may be unintended consequences. The ability to personalize content enables advertisers to deliver messages that are more relevant to individuals. Platforms can show users content that is deemed more relevant based on their interests. This focused communication comes at the cost of not exposing individuals to alternative perspectives. As a result, rather than voters being exposed to neutral or varied content, they are more likely to be exposed to content with a partisan slant that aligns with their own views. There is a genuine concern that marketing techniques may help stoke partisanship and polarization as we increasingly see messages emphasizing the flaws, real or fictitious, of those who do not agree with us.

In addition to fueling these echo chambers, another consequence of our reliance on algorithms to advance marketing is concern about the biases that have been built into these algorithms. In this issue Jerome Williams, David Lopez, Patrick Shafto and Kyungwon Lee [20] discuss the biases that can arise from leveraging consumer data for marketing purposes, and propose that the solution lies in diversifying the workforce of technology companies.

\section{A Regulatory Imperative?}

Marketing as a discipline has become more data-driven as finegrained consumer data has become readily available. While consumer profiles were once reliant on product registration and demographic information, marketers now have wideranging information than spans from media consumption to online activities, such as which websites were visited and what was posted on social media. As techniques such as machine learning and deep learning become more common within marketing, the ability to segment consumers and deliver highly customized and personalized [10] marketing content will only improve. If we were to ignore the societal implications of this and focus solely on the efficiencies that this would create for organizations, we may be able to come to the unequivocal conclusion that such efficiencies are to be welcomed.

The purview of marketing, however, is broader than selling financial services or consumer packaged goods [9]. The idea underpinning this special issue is that marketing can be used to promote legislative agendas, solicit donations and votes, but more broadly it change the world. Recognizing the power of marketing means we should also accept that the implementation of marketing may have unintentional impacts beyond its intentions. For example, targeted marketing may increase 
information asymmetries, reinforcing divisions between groups and challenging our perceptions of truth.

Regulators have begun to question the way in which data is collected from consumers. Such transparency, fostered by recent legislation, such as GDPR in the EU and CCPA in California, make consumers more aware of the exchange associated with digital interactions. The mandated disclosures in these laws, and request for consent, may affect marketing practice going forward. But, how far do such regulations need to go? Is it sufficient to advise consumers that their data is being collected? Should online content that has been curated based on data acquired about an individual also come with a prominent disclosure that alternative viewpoints are not being presented because the presented content was deemed more relevant? Or should publishers be required to present these alternative perspectives in specified contexts such as political campaigns? The importance of these questions should transcend journal articles and classroom discussions, as these decisions will dictate how marketing as a discipline operates. We would encourage marketers, both academics and practitioners, to grapple with these questions. Given the extent to which marketing is part of political campaigns' arsenals, and even the toolbox of marketers beyond the traditional political realm, it is imperative that we think more broadly about the positive and negative effects that these tools may have.

\section{Compliance with Ethical Standards}

Conflict of Interest On behalf of all authors, the corresponding author states that there is no conflict of interest.

\section{References}

1. Bendle NT, Nastasoiu M-A (2014) Primary elections and US political marketing. In: Lees-Marshment J, Conley B, Cosgrove K (eds) Political marketing in the United States. Routledge USA, New York, pp 85-111

2. Berman R, Melumad S, Humphrey C, Meyer RJ (2019) A tale of two Twitterspheres: political microblogging during and after the
2016 primary and presidential debates. J Mark Res in Advance. https://doi.org/10.1177/0022243719861923

3. Bump P (2018) All the ways Trump's campaign was aided by Facebook, ranked by importance. Washington Post March 22

4. Cillizza C (2007) Romney's data cruncher. Washington Post July 5

5. Draper K, Creswell J (2019) Colin Kaepernick 'Dream Crazy' Ad Wins Nike an Emmy. New York Times September 16th

6. Fossen B, Schweidel DA, Lewis M (2019) Examining brand strength of political candidates: a performance premium approach. Cust Needs Solut XX:XX

7. Hydock C, Paharia N, Weber TJ (2019) The consumer response to corporate political advocacy: review and directions. Cust Needs Solut XX:XX

8. Kotler P (1975) Overview of political candidate marketing. Adv Consum Res 2:761

9. Kotler P, Levy SJ (1969) Broadening the concept of marketing. J Mark 33:10. https://doi.org/10.2307/1248740

10. Kumar V, Rajan B, Venkatesan R, Lecinski J (2019) Understanding the role of artificial intelligence in personalized engagement marketing. Calif Manag Rev 61:135-155

11. Lees-Marshment J (2019) Marketing scholars and political marketing: the pragmatic and principled reasons for why marketing academics should research the use of marketing in the Political Arena. Cust Needs Solut: $1-8$

12. Lovett MJ (2019) Empirical research on political marketing: a selected review. Cust Needs Solut XX:XX

13. Malcolm H (2016) More than 700,000 pledge to boycott target over transgender bathroom policy. USA Today April 25

14. McGinniss J (1988) The selling of the president, 2nd edn. Penguin Books, New York

15. Moorthy S (2019) On marketing strategy in electoral politics. Cust Needs Solut XX:XX

16. Penn M, Zalesne EK (2007) Microtrends: The small forces behind tomorrow's big changes. Twelve, 2007. Twelve, New York

17. Schoenmueller V, Netzer O, Stahl F (2019) Polarized America: going beyond political partisanship to preference partisanship

18. Thomson M (2006) Human brands: investigating antecedents to consumers' strong attachments to celebrities. J Mark 70:104-119

19. Wedel M, Kannan PK (2016) Marketing analytics for data-rich environments. J Mark 80:97-121

20. Williams JD, Lopez D, Shafto P, Lee K (2019) Technological workforce and its impact on algorithmic justice in politics. Cust Needs Solut XX:XX

21. Zhong N, Schweidel DA (2019) Capturing changes in social media content: a multiple latent changepoint topic model

Publisher's Note Springer Nature remains neutral with regard to jurisdictional claims in published maps and institutional affiliations. 